DOI: $10.5216 /$ racs.v4.59366

\title{
Los resumenes escolares y la mejora de la práctica educativa: en el contexto de la cultura hñahñu
}

Antonio Carrillo Avelar ${ }^{1}$

\section{RESUMEN}

El presente trabajo parte de la concepción de Stardif (2004:112) sobre docencia la cual considera como un saber que dan los actores razones para actuar tal como lo hacen, teniendo en cuenta la realización de ciertas finalidades. Es decir es un saber que ejercen ciertos profesores sobre las personas con el fin de formarlo en función de ciertas representaciones... que se da en un saber y las consecuencias de una acción. En este caso se estudió una representación (Lefebrve, 1983) su estructura y orientación que ejerció un docente hñähñu sobre la enseñanza de los resúmenes escolares en grupo de sexto año de una Escuela Intercultural bilingüe, en la región del Valle del Mezquital, del Estado de Hidalgo México, a través de mostrar las implicaciones académicas y culturales que subyacen a un planteamiento didáctico, así como las derivaciones formativas sobre la manera de afrontar este proceso educativo y la búsqueda de elementos para crear una nueva representación didáctica. Metodológicamente el trabajo se centró en los lineamientos para realizar estudios de casos propuestos por a Stake(1999). Los instrumentos empleados para realizar el estudio sobre el aula fueron recuperados del trabajo de (Candela, 1999), como la observación, el diario de campo y la elaboración de mapas conceptuales elaborados ex profeso para valorar las implicaciones de este hecho formativo. Los resultados de esta investigación académica, permiten mostrar las implicaciones existente en la construcción de una representación (Lefebrve, 1983) sobre las creencias en que un docente indígena parecen asentar a sus prácticas, didácticas entre ellas: el manejo de las lecciones y consideran quienes son los mejores alumnos para elaborar resúmenes escolares, en este contexto, resulta significativo analizar los pocos elementos socioculturales y didácticos que toma en cuenta, para realizar esta afirmación académica, y la urgente necesidad de crear una nueva representación para su enseñanza.

PALABRAS Clave: Representaciones. Resúmenes escolares. Actividades académicas del profesor. Actividades a académicas de los niños.

\footnotetext{
${ }^{1}$ Pos-doctor en Educación por la Universidad de Sáo Paulo, Brasil: Doctor en Ciencias Antropológicas por la Universidad Autónoma Metropolitana (México) Profesor e investigador del Programa de Posgrado de la Universidad Pedagógica Nacional, y profesor del Programa de Posgrado en Pedagogía de la UNAM y profesor invitado del Programa de Pos-graduación Interdisciplinar en Derechos Humanos, de la Universidad Federal de Goiás, Brasil.
} 


\section{Os resumos escolares e a melhora da prática educativa: contexto da cultura Hñahñu}

\section{RESUMO}

O presente trabalho parte da concepção de docência como um saber (Stardif, 2004: 112) que dá, aos atores, razões para agirem como agem, levando em conta a realização de certos propósitos. Ou seja, tratam-se de conhecimentos que os professores exercem sobre as pessoas para formá-las em função de certas representações. Neste caso, estudou-se uma representação (Lefebrve, 1983), sua estrutura e orientação exercida por uma professora Hñähñu, no ensino de resumos escolares, em uma turma de sexto ano, de uma Escola Intercultural bilíngüe, da região do Vale do Mezquital, no estado de Hidalgo, México, evidenciando as implicações acadêmicas e culturais que fundamentam uma abordagem didática, bem como suas derivações formativas no enfrentamento desse processo educacional e na busca de elementos para criar uma nova representação didática. Metodologicamente, o trabalho centrou-se nas diretrizes propostas por Stake (1999) para a realização de estudos de caso; e em Candela (1999), para a realização de estudos de caso em sala de aula, recorrendo à observação, ao uso do diário de campo e à elaboração de mapas conceituais, criados para avaliar as implicações desse fato formativo. Os resultados dessa pesquisa nos permitem mostrar as implicações na construção de representações e nas crenças que um professor indígena parece estabelecer em suas práticas didáticas, dentre elas: o manejo das suas aulas e a definição de quem são os melhores alunos para elaborar resumos escolares e, neste contexto, é significativo analisar os poucos elementos sócioculturais e didáticos que levam em conta, para fazer essa afirmação acadêmica, e a necessidade urgente de criar uma nova representação para o seu ensino (Lefebrve, 1983).

Palavras-chave: Representações. Resumos escolares. Atividades acadêmicas do professor. Atividades acadêmicas de crianças.

El estudio no se mide por el número de páginas leídas en una noche, ni por la cantidad de libros leídos en un semestre. Estudiar no es un acto de consumir ideas, sino de crearlas y recrearlas.

Paulo Freire

\section{Introducción}

Pensar un proceso formativo para los pueblos originarios, hace insoslayable repasar la importancia de recuperar la diversidad cultural y la lingüística, como un recurso muy importante para promover una práctica educativa, para niños que esta insertos en esta realidad formativa. que si bien hoy en día está considerado un derecho humano, contemplado en la legislación mexicana (INALI,2003), la realidad es que pocos docentes del medio indígena, 
tienen presente esta premisa académica, en el contexto de cómo hacerlo ejercer y hacer funcionar las escuelas públicas que tienen como base la defensa de los derechos culturales de estos pueblos.

Con frecuencia existe la representación ${ }^{2}$ como hechos sociales que son construidos por los habitantes de las comunidades indígenas, los cuales conciben que la educación es una práctica mágica, en donde con frecuencia se considera que solo basta enviar los niños a la escuela, para que ahí se le dote de todas las herramientas para ser formado. Lo que a menudos se olvida que la historia vivida de sus docentes y la relación escuela- sociedad es la que con frecuencia determina lo que sucede en su accionar cotidiano de la misma (Cervantes, 1998). Existe también en el medio indígena la creencia que las mejores escuelas de educación primaria son aquellas llamadas escuelas generales, donde no se enseña educación bilingüe y poco se hace alusión a las prácticas culturales de sus pueblos y que sin embargo están preocupadas por cumplir al pie de la letra por lo marcado en los planes y programas oficiales, están muy bien pintadas, donde los elementos formales se cumplen como la puntualidad, utilizan uniformes y ropa deportiva como pants, tenis, entre otros aspectos, muy vinculados a la cultura occidental

Esto hechos también son aplicables a lo que sucede en la vida cotidiana de las escuelas hñahñus, los cuales tienen particularidades propias y formas de aprender específicas y que al parecer, muchas personan piensan, por el solo hecho de tener profesores indígenas que han sido formados en el mismo contexto, y que muchos de ellos eran personas que realizaban diferentes actividades productivas en la región, fueron habilitados para ser docentes, por lo tanto se consideraba que éstos van a actuar en consecuencia para superar las prácticas formativas de sus instituciones educativas, recuperando los contextos de la diversidad cultural que están insertos, sin embargo en los hechos no sucede así como lo mostraremos a lo largo del presente trabajo.

En las dos últimas décadas, se habla de la importancia de aprovechar la diversidad cultural como una ventaja formativa (Morollón, 2003);(Essomba,2007) para el beneficio de sus usuarios. Sin embargo, se requiere también mirar lo que sucede al interior se sus aulas y sobre todo del manejo didáctico que se realiza de las diferentes competencia académicas que

\footnotetext{
${ }^{2}$ Una representación según Lefebvre (1993:29), es un hecho social, psíquico, político, de carácter específico, que permiten explorar, e identificar lo que es posible cambiar. Es decir explorar e identificar aquello que lo bloquean y que sin embargo es posible cambiar. Desde esta perspectiva adoptamos el término representación, como la posibilidad de cambiar una práctica de enseñanza, a través del enfoque comunicativo funcional, puedan los resúmenes ser objeto de construcción y reconstrucción.
} 
requieren sus estudiantes para poder vivir en su ámbito sociocultural y en este mundo global en que nos encontramos insertos. Tener en cuenta estos aspectos, tal vez ayudaría en cierta medida a reflexionar a los docentes indígenas sobre cómo se manifiesta esta representación y en consecuencia valorar las implicaciones formativas que tienen este quehacer pedagógico y coadyuvar a la mejora del quehacer didáctico de este campo educativo.

En otras palabras, prepararnos en contexto de diversidad y al mismo tiempo para este mundo global, pareciera que hay dos caminos, uno en donde solo basta con homogenizarnos y borrar todas las diferencias culturales existentes para lograr un proceso formativo y el otro el trabajar las diferencias culturales con la idea, que los pueblos sigan conservando sus prácticas formativas, como un quehacer de museo, al margen de los que sucede en otros espacios sociales (Sagastizabal, 2009). Estas dos formas extremistas de ver la realidad educativa en el ámbito de los pueblos originarios es bastante común, y ambas se olvidan que la esencia de la tarea educativa es crear otra representación (Lionel y Mozejko,2009) que posibilite potencializar todas las capacidades propias del ser humano y llevarlas a niveles superiores de formación, en donde todos los pueblos sin distinción cultural puedan competir académicamente, sin menoscabo de su diferencias culturales.

Hablar del poder de las representaciones implica en nuestro enfoque :a) ubicar las representaciones en el ámbito de las relaciones sociales; b) entender que estas relaciones se plantean entre agentes definidos de su identidad social y capacidad diferenciada de relación por el conjunto de propiedades eficientes que poseen en el sistema de relaciones en el que intervienen; c) afirmar que en las relaciones sociales siempre se involucra sentidos, representaciones, y se pone en juego también la pretensión de ser escuchado , aceptado sin imponerse(Lionel y Mozejko,2009:79).

En este sentido todo niño está obligado a tener el dominio de competencias académicas a lo largo de todo su proceso formativo que le permitan adquirir y producir conocimiento para el trabajo intelectual, donde los resúmenes escolares tienen un papel muy importante.

El desafío sigue siendo el mismo: formar niños lectores-comprendedores de textos y escritores-productores de textos polivalentes y autónomos. Y Para lograrlo formar: niños que al terminar su escuela primaria, sean todos capaces de actuar, de reaccionar o de hacer actuar, a partir de todo tipo de escritos: - niños que (por haberse progresivamente, explícitamente y frecuentemente entrenado para hacerlo) sean todos capaces de elaborar y de construir sus proyectos y su propia actividad de lectores/productores de textos. Muy felizmente, todo esto se aprende y, por lo tanto, todo esto se enseña (Jolibert y Sraïki, 2006:13). 


\title{
1 Justificación
}

El resumen escolar, en todos los ámbitos educativos, es un importante artefacto didáctico $^{3}$ que es preciso manejar con soltura para alcanzar el éxito, académico y profesional en sociedades globalizadas como la nuestra, en las que el acceso al conocimiento y la información están altamente mediados por ella. Hoy día, todavía el peso fundamental en los procesos de enseñanza y aprendizaje recae en la escuela.

\begin{abstract}
Ante una realidad tan dinámica y compleja, en una sociedad en la que el conocimiento generado por los especialistas se produce a ritmos más acelerados que las posibilidades de efectivizar cambios curriculares que los incorporen en tiempos cortos, se enfatiza la enseñanza de los procedimientos del como conocer y del cómo enseñar.(Sagastizabal, 2009:39).
\end{abstract}

También uno de los objetivos fundamentales que los sistemas letrados persiguen desde las primeras etapas de la escolarización, es el fomento de la lecto escritura ${ }^{4}$ entre otras competencias para el trabajo intelectual. La forma de abordar este importante contenido en los contextos educativos ha generado significativos acuerdos y desencuentros en la comunidad escolar en cuanto a la importancia de como formar verdaderos usuarios, que acudan a la lectura y escritura como un recurso importante que forme parte de su cotidianidad. Es decir es urgente tener una nueva representación en donde los niños vean en su formación hábitos académicos centrados en la interpretación y la elaboración de textos como parte de su vida diaria.

Desde la concepción constructivista (Olmos y Carrillo, 2009), el aprendizaje de los resúmenes escolares se entiende como una construcción activa de los pequeños. En sus escuelas indígenas se aboga por crear contextos altamente formativos y ricos en material impreso como es el caso de los libros de texto gratuito, que permitan a los pequeños apropiarse de ese objeto de aprendizaje a partir de la interacción con sus compañeros. Hoy la didáctica cotidiana plantea la importancia de partir de situaciones cotidianas, para que los

\footnotetext{
${ }^{3}$ Un artefacto didáctico, también puede ser concebido como un artefactos culturales el cual tiene una tiene una unidad material y simbólica al mismo tiempo. Es decir los artefactos son representaciones culturales integradas por símbolos aprendidos y sistemas compartidos de significado. Ni los artefactos, ni las acciones existen aislados. Más bien, unos y otras están entretejidos entre sí y con los mundos sociales de los seres humanos que median para formar amplias redes de interconexión (Cole, 1999:115).

${ }^{4}$ En el campo de la educación para los pueblos originarios se ha aceptado la importancia de iniciar un proceso de alfabetización en lengua materna y posteriormente continuar con un sistema de planeación lingüística (Carrillo, Herrera, y Montero:2017).
} 
niños con el fin de estimulen y potenciar el aprendizaje de los resúmenes escolares en su propio contexto de uso ((Jolibert y Sraïki,2006:27). Desde esta concepción se entiende que el conocimiento es una re-elaboración de la experiencia que implica establecer relaciones entre lo que ya se sabe y lo que se quiere aprender (Jolibert y Jacob, 2015). Por su parte, autores de la concepción sociocultural plantean que el lenguaje escrito es un artefacto cultural muy relevante que constituye un sistema simbólico, y que representa en gran medida al lenguaje oral, otro sistema simbólico más primario que a su vez representa a la realidad (Vigotsky, 1978; 1982). A partir de esta idea, Vigotsky resalta la importancia de hacer pasar a los niños por sistemas simbólicos primarios, como el lenguaje oral o el dibujo, para llegar a comprender el potencial simbólico del lenguaje escrito y consecuentemente con el desarrollo de competencias para el trabajo intelectual. También desde esta corriente se ha resaltado el valor de los textos escolares como una forma de facilitar la comprensión del mundo físico y social a los niños (Jolibert, Jacob, 2015:278) en este sentido, se aboga por utilizar esta forma de expresión como un medio para ayudarles a manifestar sus pensamientos e ideas y consecuentemente en fundamentarlas. Los planes y programas coinciden en la importancia de ir dosificando esta competencia desde el primer año de ingreso a la primaria.

En el caso de las escuelas indígenas en México, estas se han visto beneficiadas por diferentes reformas en artículos y ratificación de acuerdos, por ejemplo en el año de 1990. México ratificó el Convenio 169 sobre pueblos indígenas y tribales en países independientes de la Organización Internacional del Trabajo (OIT), que reconoce los derechos de los pueblos indígenas y en su artículo 27 establece:

Que los programas y los servicios de educación destinados a los pueblos interesados deberán desarrollarse y aplicarse en cooperación con estos, a fin de que respondan a sus necesidades particulares; asimismo tendrán que abarcar su historia, sus conocimientos y técnicas, sus sistemas de valores y todas sus demás aspiraciones sociales, económicas y culturales.

La ratificación de este convenio es un antecedente para la reforma al artículo $2^{\circ}$ de la Constitución Mexicana en 1992:

La nación tiene una composición pluricultural sustentada originalmente en sus pueblos indígenas que son aquéllos que descienden de poblaciones que habitaban en el territorio actual del país al iniciarse la colonización y que conservan sus propias instituciones sociales, económicas, culturales y políticas, o parte de ellas. (Constitución Política de los Estados Unidos Mexicanos, reforma del 28 de enero de 1992.) 
Esta reforma originó la creación de la Ley General de Derechos Lingüísticos de los Pueblos Indígenas el 13 de marzo de 2003, como elemento jurídico para el reconocimiento "de los derechos individuales y colectivos de los integrantes de las sesenta y ocho agrupaciones lingüísticas en México". (Diario Oficial de la Federación, 13 de marzo del 2003).

Aunque dispongamos de información suficientemente documentada acerca de cómo deberían ser las buenas prácticas de enseñanza donde se recuperen sus particularidades culturales y lingüísticas que condujeran al fomento de enseñanza y aprendizaje para el trabajo intelectual en nada se contrapone a este ideal educativo, sino al contrario se convierte en un vínculo importante para el desarrollo de competencias para el trabajo intelectual que todo niño hñahñu debe manejar.

El que sean contenidos escolares aprobados por la Secretaria de Educación pública, nada nos garantiza que tales prácticas para el fomento del trabajo intelectual estén bien enseñadas como habilidad académica para el aprendizaje y enseñanza de las demás asignaturas del currículo formal de educación primaria. Es decir que se ponga en práctica en los escenarios reales de enseñanza dada su importancia formativa ${ }^{5}$. En la cotidianidad de las escuelas no es posible mantener la certeza de que los docentes dispongan de la trascendencia de esta habilidad académica para los estudiantes en formación en el nivel de educación básica. Por ello, resulta fundamental indagar qué forma toman y cómo se vertebran los procesos reales de aprendizaje y enseñanza al interior de las aulas, con miras al fomento de esta competencia o el fomento de un ajuste a la manera de cómo enseñar los resúmenes en los salones de clase.

Analizar una representación a través del estudio de una clase sobre la enseñanza de los resúmenes, se consideró importante, porque esta competencia académica poseé en su interior, el dominio de varias habilidades académicas importante para cualquier niño, independientemente de su contexto cultural.

Los procesos de enseñanza-aprendizaje sobre los resumes escolares en las aulas observadas en el contexto de las escuelas hñähnú, se pudo advertir en estos espacios se

\footnotetext{
${ }^{5}$ El resumen es una representación abreviada del contenido de un texto, es decir, es un escrito que se construye a partir de otro y consiste en extraer lo que consideramos más importante de un tema. El propósito del resumen es informar y por tal motivo no emite opiniones, juicios de valor e interpretaciones. El resumen recaba las ideas principales discriminando las ideas secundarias, lo que da por resultado un escrito conciso, completo y preciso que condesa de manera coherente lo esencial del texto original Cortés, R. (2011). Operaciones Textuales: Resumen. México: Portal Académico del CCH/UNAM. Recuperado de http://portalacademico.cch.unam.mx/alumno/tlriid2/unidad2/operacionesTextuales/resumen (julio, 2013).
} 
configuran bajo un complejo entramado de relaciones de muy distinta a los enfoques que promueven las reformas educativas, la mayoría recupera las formas en que fueron enseñados sus docentes, es decir hay un divorcio entre planificación que propone el plan y programa y la cotidianidad de enseñanza del aula, entre lo que parece relevante hacer, desde la lógica del enfoque previsto que en este caso es el llamado enfoque comunicativo funcional ${ }^{6}$ y aquello constituye la práctica real. Situación que dificulta significativamente el empleo con fines formativos de esta competencia académica en la cotidianidad de estas instituciones educativas.

En el ámbito de formación de los pueblos originarios hoy más que en otras épocas existe la necesidad de una formación intelectual indígena diferente. Los docentes hñähnú en particular y los docentes en general, más que en otros tiempos, deben de incorporar a su quehacer cotidiano, los enfoques recientes para su enseñanza y los conceptos de diversidad y preparación plurilingüe cuando trabaje con niños hñahñus.

En este contexto cobra relevante importancia la enseñanza de los resúmenes escolares, debido a que en su interior incluyen varias competencias académicas específicas que el estudiante tiene que saber manejar como son: es saber leer tanto en voz alta, como en silencio; saber extraer las ideas más relevantes de un texto; saber hacer una síntesis con sus propias palabras y por último saber dar una opinión personal sustentada el documento trabajado. Todo esto en un marco de ir fortaleciendo un trabajo intelectual autónomo, muy necesario para la vida intelectual de los niños hñähnú.

El conocimiento de este proceso académico, permite entender que el docente está obligado a conocer cada una de estas fases y hacer una planeación que le permita al niño entender de qué se trata, y que todo esto es un proceso que se va adquiriendo poco a poco. Consecuentemente esto no se puede aprender en una sola clase, como se pudo apreciar la sesión de aula analizada.

\footnotetext{
${ }^{6}$ El enfoque comunicativo funcional, se apoya en la noción de uso del lenguaje y la comunicación de sus actores sociales. Este enfoque toma como eje la perspectiva pragmática, sociolingüística y discursiva sobre la lengua que busca analizar la actuación lingüística y las prácticas comunicativas en general, como un conjunto de normas y estrategias de interacción social orientada a la negociación cultural de los significados en el seno de situaciones concretas de comunicación. Lomas (1999), Cómo enseñar a hacer cosas con las palabras. Teoría y práctica de la educación lingüística. Vol. II, Barcelona, Paidós.
} 


\section{Escenario de trabajo}

La palabra hñahñu ${ }^{7}$ está formada por dos partículas: hña(significa hablar) y hñu (significa nariz). Podemos decir que las personas que forman el pueblo hñahñu son aquellas que hablan su lengua de manera nasal (DGEI, 2017). En la actualidad ocupan un territorio discontinuo que se extiende por los estados de México, Hidalgo, Querétaro, Guanajuato, Michoacán, Tlaxcala, Puebla y Veracruz. Todos estos estados se encuentran en el centro del país. De manera regional este pueblo puede agruparse en cuatro grandes espacios geográficos: el Valle del Mezquital, la Sierra Madre Oriental, el Semi-desierto queretano y el norte del estado de México. La región del valle del mezquital, está compuesta, por 27 municipios, y se caracteriza por un clima semidesértico, muy caliente durante el día y con bajas temperaturas por la noche. Hay escasa precipitación fluvial y la vegetación es escasa. La temperatura promedio es de $18^{\circ} \mathrm{C}$; durante enero, el mes más frío, se registra una temperatura promedio de $13^{\circ} \mathrm{C}$, y de $21^{\circ} \mathrm{C}$ en los meses más calurosos, de junio a agosto.

Dada su situación territorial y de marginación socioeconómica, los hñahñu han buscado estrategias que les permitan mejorar esta situación a través de vincularse laboralmente a las grandes ciudades, como la Zona Metropolitana de la Ciudad de México, la ciudad de Puebla, Toluca y San Juan del Río Querétaro, lugares a donde han tenido que migrar o van vender sus trabajos artesanales. Muchos otros habitantes también han ido en búsqueda de una mejor situación económica irse a trabajar a los Estados Unidos de Norteamérica, como resultado de esta circunstancia hoy permite ver en las diferentes regiones donde viven los hñähñús, grandes y modernas casas habitacionales, que se construyen con el dinero que envían los migrantes.

Es importante destacar que los migrantes agrícolas y urbanos, representantes del pueblo hñähnú cada vez que terminan de trabajar en estos espacios, con frecuencia regresan a sus comunidades para para participar en las actividades comunales, mejorar los camino, reparar las escuelas, o bien, para ayudar en la elaborar artesanías o producir tejidos o bordados para después venderlos en los mercados regionales, o también para ocuparse de sus propios cultivos. En términos generales, se puede decir que los ñhäñhú, no pierden los lazos de comunicación que los vinculan con sus comunidades.

\footnotetext{
${ }^{7}$ El pueblo ñhahñu e, también conocido como otomí. La palabra otomí también está formada por dos partículas que son de origen náhuatl: otocac(significa el que camina) y mitl(significa flecha). Hay otro dato: totomitlquiere decir "flechador de pájaros", "flechador de aves". Si reunimos los datos anteriores, podemos decir que otomí significa "cazador que camina cargado de flechas", o "flechador que camina"(Chapela, 2005:9-10).
} 
El sistema educativo a nivel primaria se encuentra organizado por tres tipos de modalidades educativas: 1.- Escuelas CONAFE Consejo Nacional de Fomento Educativo es un organismo público descentralizado de la Secretaría de Educación Pública (SEP) de México, con personalidad jurídica y patrimonio propios abocadas a atender a los niños de las regiones más alejadas en el Valle del Mezquital y generalmente están atendidas por un instructor comunitario(generalmente son egresados de escuela secundaria o estudiantes de bachillerato que se habilitan para cumplir las función básicas de la educación primaria).2.Las llamadas Escuelas Primarias Generales están coordinadas por el Sistema Federal de Escuelas Primarias del Estado de Hidalgo y se caracteriza porque la mayoría de sus docentes fueron formados en las escuelas Normales Estatales o Rurales 3.- Las escuelas primarias interculturales bilingües, coordinadas por la Subdirección de Educación Indígena, este subsistema se caracteriza porque todos sus docentes son hñahñus, en un principio desempeñaban varios oficios o eran amas de casa, formados en cursos intensivos a través de la Universidad Pedagógica Nacional y las Normales Superiores ubicadas en varios estados de la República. En este tercer tipo se ubican las escuelas motivo de este trabajo académico.

Las escuelas primarias donde se realizó el estudio eran escuelas de tiempo completo, es decir se contaban con seis grados y se escogieron a sugerencia de los supervisores, ya que ellos consideraban que eran las instituciones con mejor desempeño académico. El grado que se toma como, base fueron del grupos de sexto grado, porque éstos permitían valorar mejor el tipo de educación que recibían los niños hñahñus.

Se debe de destacar también, que el estudio se centró también en el hecho de identificar al que se consideraba era el mejor docente, según el criterio de sus demás compañeros. Ellos consideraban era un excelente profesor porque con frecuencia sus alumnos eran premiados en los eventos que organizaba la supervisión escolar; también le gustaba hacer innovaciones en el aula, y le agradaba apoyar a sus compañeros en la puesta de bailables regionales. 
Figura 1 - Salón de clases de un maestro hñahñu exitoso.

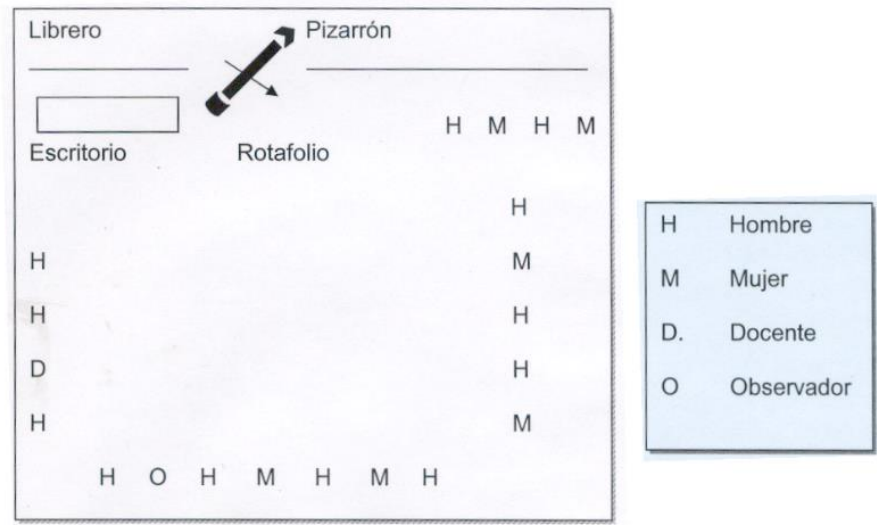

Por estrategia metodológica, la clase seleccionada para realizar el estudio, fue aquella que se ubicaba casi al final del año escolar. El grupo estaba integrado por aproximadamente ocho niños y diez niñas, la mayor parte de ellos eran bilingües, con mayor predominio del en español.

\title{
3 Metodología
}

Para explorar a fondo la representación que sustentan al profesor observado, se optó por recabar información intensiva y extensiva sobre su trabajo académico. Es decir se efectuó, un estudio de corte interpretativo en su vertiente cualitativa siguiendo los planteamientos teórico-metodológicos que propone Erickson (1999) con rasgos de la etnografía del aula (Candela,).Todo esto, todo esto también ubicados en los postulados teórico- metodológico que propone Stake $(1999)^{8}$, para hacer un estudio de caso.

\begin{abstract}
La visión sobre los estudios de casos que presento...parte de un modo de los métodos naturalistas, holísticos, etnográficos, fenomenológicos y biográficos. No me interesan tanto los estudios cuantitativos en los que se destacan un conjunto de mediciones del caso, una serie de variables descriptivas, comunes en medicina y en educación especial. Tampoco me inclino por la creación de estudios de casos con propósitos instructivos, los que se emplean normalmente en las escuelas de comercio y en derecho. Se tratan de cuestiones que merecen estudios propios. Aquí presentamos, de forma breve un modo disciplinado y cualitativo de investigación en el caso singular. El investigador cualitativo destaca las diferencias sutiles, la secuencia de los acontecimientos en su contexto, la globalidad de las situaciones personales (Stake, 1999:66).
\end{abstract}

\footnotetext{
${ }^{8}$ Estudiamos un caso cuando tiene un interés muy especial en sí mismo. Buscamos el detalle de la interacción con su contexto. El estudio de casos es el estudio de la particularidad y de la complejidad de un caso singular, para llegar a comprender su actividad en circunstancias importantes (Stake, 1992:66).
} 
En esta misma perspectiva se realizaron diversas actividades de investigación más amplia $^{9}$ sin embargo aquí se concretó en principalmente en lo que sucedía en un salón de clase .Uno de los medios utilizados para investigar la cotidianidad de la enseñanza de los resúmenes escolares en las aulas hñahñús, consistió en observar de manera cotidiana el enfoque constructivista (Solé y Coll, 2007) para la enseñanza de sus clases. Esta mecánica de trabajo continuaba una vez que se encontraba algo relevante como criterio de validación de los hallazgos. Es decir se procedía a solicitarle a otro docente, de otra escuela del mismos sector educativo, que pusiera en práctica, la misma competencia académica. Por ejemplo al profesor de la segunda escuela se le pidió que enseñara el resumen escolar en su salón de clase, tomando en cuenta, que se requería de una buena clase y posteriormente se procedía a observar la cotidianidad de enseñanza en un aula.

Subsecuentemente se procedía a entrevistarlos de manera informal pidiéndoles que explicaran aquello que los maestros dicen hacer; es decir, cuáles eran sus ideas en torno a la enseñanza y aprendizaje de los resúmenes y en general cuales eran sus concepciones que los docentes mantienen sobre el enfoque recomendado para su enseñanza. Esto suponía, en definitiva, a cuál era la representación didácticas que sirven de soporte a sus sistemas de creencias y sustentos que los profesores dicen tener.

Intentamos ser un poco más explícitos: necesitamos teorías que nos sirvan de referente para contextualizar metas y finalidades: para planificar la actuación: para analizar su desarrollo e irlo modificando en función de lo que ocurre y para tomar decisiones acerca de las adecuaciones de todo ello (Solé y Coll, 2007:9).

Hacer un resumen en el contexto de un salón de clases, significó analizar a detalle el diseño de una secuencia didáctica de elaboración de resúmenes escritos a partir del estudio de los procesos constructivos que empleaban los niños, los cuales se consideraba necesario conocer, para analizar los problemas que enfrentan los alumnos ante el empleo de esta competencia real y los criterios didácticos que emplea el docente.

Los alumnos trabajaron con el texto de historia que presentaba sobre el contenido escolar denominado La Revolución Mexicana, la clase consistió en repartir a todo el grupo esta lección y pedirles después que ellos realizaran un resumen concreto, de la parte que les tocaba. Aquí los niños tuvieron la oportunidad de leer el texto y después darle a conocer a su maestro su resumen y él procedía a corregirlo. La clase duro aproximadamente dos horas.

\footnotetext{
${ }^{9}$ El trabajo de investigación se organizó a partir de tres ejes temáticos: la vida cotidiana de las aulas, la producción escrita, y la resolución de problemas matemáticos.
} 
Los objetivos y preguntas de investigación, que apunta a mostrar que con frecuencia en el ámbito de la educación indígena, muchos docentes no están convencidos de que existan niños que sean monolingües en su propia lengua, porque implica reproducir el estigma de la discriminación social y de manera inconsciente caen en prácticas segregación, de sus alumnos, en contraposición a la idea de aceptar la existencia de la diversidad linguística y cultural (Perlo, 2007). Es decir en teoría un profesor que trabaje en este ámbito, debe de estar preparado para resolver este tipo de prácticas de diversidad cultural que se dan en las aulas hñahñu y de establecer estrategias que ayuden a la defensa de sus derechos lingüísticos.

Por otra parte el docente está obligado comprender bien todos los elementos didáctico implícitos en la elaboración de resúmenes escritos a partir del estudio de los procesos constructivos de los niños. Es decir es necesario conocer tanto los problemas que enfrentan los alumnos ante la tarea como su competencia real para llevarla a cabo y que su tarea consiste en formar niños lectores y productores de sus propios textos académicos.

\footnotetext{
Del mismo modo que consideramos que en el aprendizaje intervienen los aspectos de tipo afectivo y relacional y en general todo aquello que suele incluirse en las capacidades de equilibrio personal, estamos convencidos de que éstas no se constituyen en el vacío ni al margen de otras capacidades. Cuando aprendemos nos implicamos globalmente en el aprendizaje, y el proceso seguido y su resultado repercute también en nosotros de manera global (Solé, 2007:26).
}

El criterio de selección de la muestra, tomó como base la consideración el desarrollo de habilidades para el trabajo intelectual que poseían los niños, hasta el momento del análisis de la lección presente. Para efectos de este trabajo, este criterio era muy relevante, ya que el estudio partió del problema educativo que los mismos docentes de manera informal señalaban, que con frecuencia los niños hñähnú, los bajan de grado escolar, cuando emigran a las grandes ciudades o a los Estados Unidos de Norteamérica, porque los docentes, que los recibían consideran que éstos no poseen la competencias académicas para el trabajo intelectual debido a que éstos consideran que los conocimientos requeridos para el nivel que se inscribían eran muy pobres.

Tomando como base lo anterior, el trabajo de investigación en el aula, se tomó como base las siguientes preguntas de investigación:

- ¿Cuáles es la representación existente del docente en torno a la enseñanza de los resúmenes, en el contexto de un salón de clases hñähnú?

- ¿Cómo construyen los niños los resúmenes escolares?

- ¿Cuáles son las estrategias que emplean para su realización? 
- ¿Qué aprendizajes específicos reportan?

- ¿Cuál es el grado de dominio de su competencia comunicativa?

\section{Desarrollo de la secuencia didáctica}

Para entender la clase motivo de este estudio, es importante tener presente que el contenido de la misma, es el resultado de dos lecciones anteriores, sobre la misma temática. Lo que aquí se muestra solo representa una pequeña parte de la clase ubicada a las 9:41 a 11:00 horas, cuando se les pide que realicen un resumen.

También hay que acotar que con lo visto, el docente cierra el tema que se había tratado en dos sesiones anteriores.

Figura 2 - Secuencia comunicativa sobre el contenido de la clase analizar.

\begin{tabular}{|c|c|c|}
\hline & ESTRATEGIA DEL MAESTRO & E. DE LOS ALUMNOS \\
\hline $9: 23$ & $\begin{array}{l}\text { El maestro prequntó a los niños qué canal veían y los invitó a } \\
\text { comentar sobre el suceso del día de aver. }\end{array}$ & $\begin{array}{l}\text { Algunos alumnos participaban en } \\
\text { la interacción. }\end{array}$ \\
\hline $9: 25$ & $\begin{array}{l}\text { El maestro narró la noticia sobre la muerte de "Paco" Stanley, } \\
\text { solicitando el apoyo del grupo. }\end{array}$ & $\begin{array}{l}\text { Los alumnos se encontraban } \\
\text { sentados en círculo dispuestos a } \\
\text { participar. }\end{array}$ \\
\hline 9:32 & $\begin{array}{l}\text { El maestro solicitó que hicieran un resumen oral sobre el asesinato y } \\
\text { al obtener poca respuesta él lo realizó. }\end{array}$ & $\begin{array}{l}\text { Los alumnos se encontraban } \\
\text { sentados en círculo dispuestos a } \\
\text { participar. }\end{array}$ \\
\hline 9:36 & $\begin{array}{l}\text { El maestro siquió insistiéndole a Juan que hiciera el resumen en } \\
\text { pocas palabras y les recomendó a los demás niños que fueran } \\
\text { pensando en cómo hacerlo. }\end{array}$ & $\begin{array}{l}\text { El grupo manifestaba extrañeza y } \\
\text { dificultad sobre la tarea que se } \\
\text { solicitaba. }\end{array}$ \\
\hline 9:39 & El maestro explicó el concepto de resumen. & \\
\hline $9: 41$ & $\begin{array}{l}\text { El maestro asiqnó trabajo académico al grupo para que éstos hicieran } \\
\text { un resumen sobre la asignatura de historia. }\end{array}$ & $\begin{array}{l}\text { Los niños se dispusieron a sacar } \\
\text { sus libros y a realizar la tarea } \\
\text { asignada. }\end{array}$ \\
\hline 10:15 & El maestro solicitó a los niños que leveran en voz alta sus resúmenes. & $\begin{array}{l}\text { Los niños por su parte } \\
\text { continuaban con la tarea asignada } \\
\text { y otros se encontraban distraídos. }\end{array}$ \\
\hline 10:50 & El maestro conceptualizó desde su escritorio la noción de resumen. & \\
\hline 10:55 & $\begin{array}{l}\text { El maestro solicitó a los niños que leyeran y contestaran la quía de } \\
\text { trabajo en la parte referente al resumen. }\end{array}$ & $\begin{array}{l}\text { Los niños realizan el ejercicio } \\
\text { solicitado. }\end{array}$ \\
\hline 11:00 & $\begin{array}{l}\text { El maestro resolvió un eiercicio de la "Guía práctica" con el apoyo del } \\
\text { grupo. }\end{array}$ & $\begin{array}{l}\text { Los niños participaron en lo } \\
\text { solicitado por el maestro. }\end{array}$ \\
\hline
\end{tabular}

Para iniciar la clase, el docente buscó que los estudiantes repasaran lo visto en la televisión y destacaran cual había sido la noticia principal y después realizaran un resumen (Ver Figura 5), es decir la clase tuvo cuatro partes: La primera significó recordarles de manera general que un resumen significa extraer las ideas principales de un texto. La segunda 
consistió en solicitarles a los niños que realizaran un resumen de la lección siete del libro de historia, motivo por el cual el repartió la mencionada lectura en cuatro partes y le pidió que cada niño, efectuara el resumen correspondiente de la sección que le tocó. El docente, recomendó que prácticamente borren toda huella del texto fuente, destacando que realicen las siguientes acciones: "escribir con sus propias palabras lo que entendieron de la lectura asignada". Es decir los invitó que produjeran, a partir de un texto fuente, un escrito que cumpliera con la premisa de ser más breve y formalmente distinto al documento leído. La tercera parte, consistió en evaluar y calificar de manera individual la lección a partir del producto elaborado. La cuarta, se complementó con otro libro guía donde se destacaban los elementos que deben de tener un resumen.

\section{Análisis de la clase}

Ejemplo de estudiantes que realizan bien un resumen - Los niños que había aprobado el docente con una calificación alta de 9.5 (como se aprecia en el ejemplo), eran aquellos que siempre participan en clase y que al parecer con frecuencia tenían una mejor posición económica, que se apreciaba en su forma de vestir.

Figura 3 - Resumen elaborado por un niño hñahñu exitoso, según el docente.

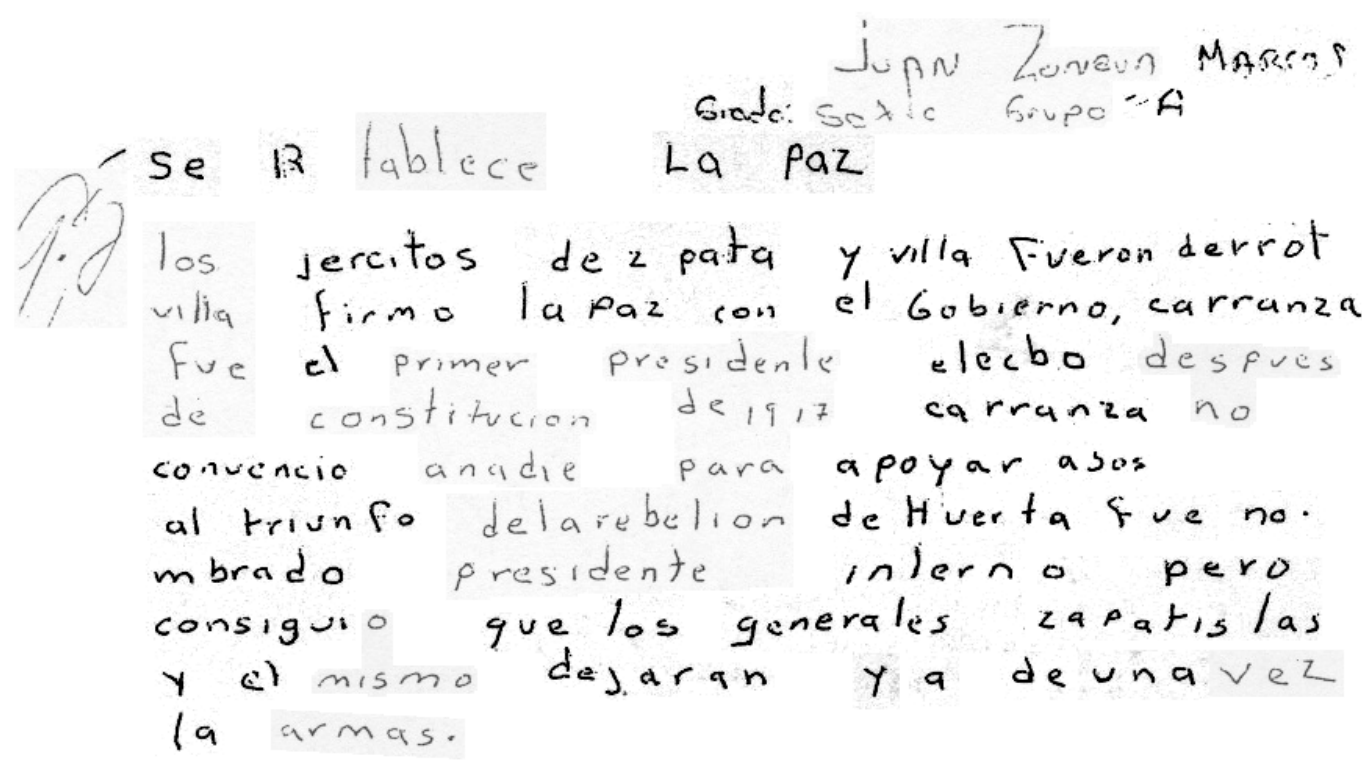


Sin embargo, analizando a detalle sus productos académicos, se apreciaba que muchos niños tergiversaban el sentido del texto, como se puede ver en el casos del niño " $\mathrm{A}$ " el suprimió elementos nucleares y necesarios en el documento. También comprobamos que no era un verdadero resumen ya que conservaban excesivos elementos secundarios. Suponemos que esto, puede estar asociado con una circunstancia habitual en el ámbito escolar, en donde el maestro está acostumbrado a evaluar a todos los niños de un grupo, por su trayectoria en clase, sin cerciorarse si éstos realmente tienen el conocimiento que supuestamente deben de manejar. Ya que a menudo, se acostumbra que lo más importante en un trabajo de aula, es promover que se vean los contenidos marcados por el programa al margen de un verdadero dominio de esta habilidad académica. Esto es importante resaltar ya que en muchas escuelas en el medio indígena el número de alumnos es reducido y consecuentemente el docente podría cuidar más el dominio de la competencia académica.

Por otra parte, al observar los procedimientos utilizados en el transcurso de la producción de los resúmenes, comprobamos que muchos alumnos ponían en juego una estrategia que consistía en leer rápidamente el texto fuente para escribir el resumen escolar, a partir de los primero que se les ocurrida, ya que para ellos, lo importante era cumplir con la tarea asignada al margen de los principios recomendados para la realización de un resumen escolar.

Ejemplo de alumnos que realizan mal un resumen - Analizando el producto o resumen elaborado por el niño "B" se pudo apreciar que en éste el docente no le anoto ninguna calificación a su trabajo.

Testimonio No1. Fragmento de la clase donde el profesor da la opinión sobre el trabajo del niño que no saben hacer resúmenes.

\begin{tabular}{|c|c|c|}
\hline $\begin{array}{l}349 \\
350 \\
351 \\
352\end{array}$ & $\mathrm{M}$. & $\begin{array}{l}\text { De hecho, éste para resumen es un poquito laborioso, porque no } \\
\text { habla de la historia, sino habla de una narración de una persona } \\
\text { que convivió con Álvaro Obregón. Entonces casi no hay ideas } \\
\text { principales. }\end{array}$ \\
\hline
\end{tabular}

Fuente: Elaboración propia, producto de una transcripción de una clase.

Dada la dinámica de la clase el niño "B" tuvo oportunidad de revisar y corregir su texto. Lo leyó detenidamente, se manifestó disconforme con el mismo y preguntó si podía volver a hacerlo. Después de un tiempo elaboró el resumen y el profesor nuevamente se lo rechazo. Dado que se estaba observando el hacer del docente, éste se atrevió a justificar el 
accionar del niño destacando que en este texto casi no hay ideas secundarias, esta afirmación la realizó cuando se le preguntó porque no había evaluado al estudiante (Ver testimonio, No.1).

Figura 4 - Resumen elaborado por un niño hñahñu con problemas de aprendizaje, según el docente.

\section{uno desemblonzede alkaroobregon}

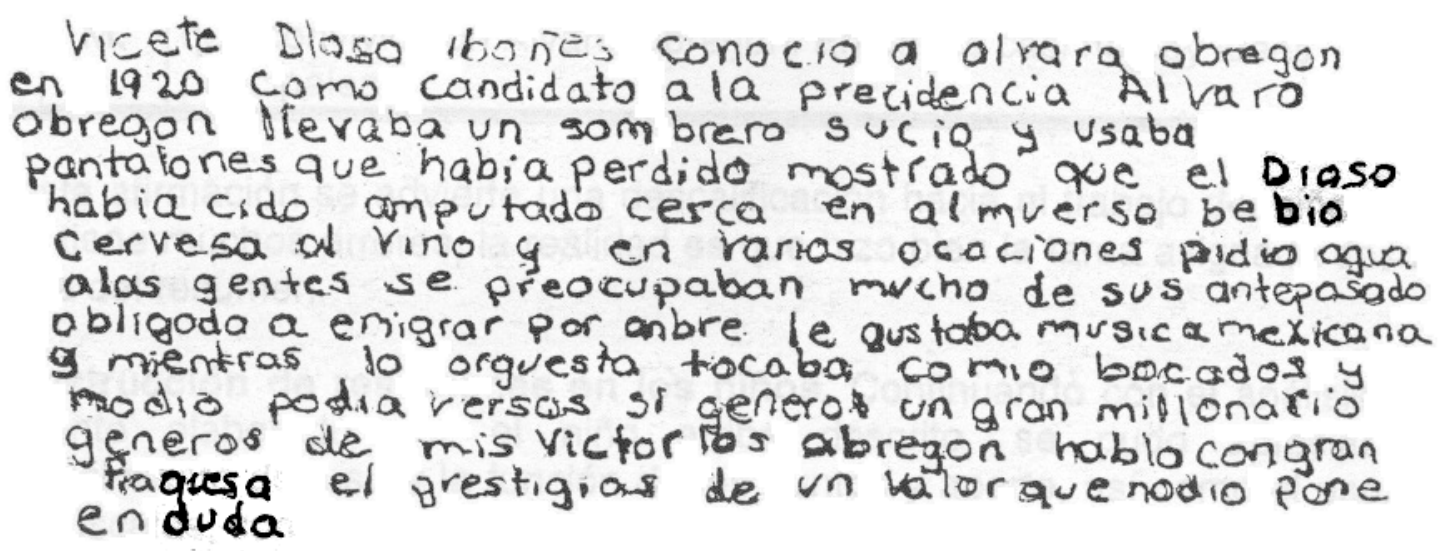

Martin Rogue Roque : grado

Esta circunstancia motivó a investigar a detalle que es lo que había sucedido. Tomando en cuenta que este niño comprendía bien el español pero se dificultaba hablarlo y mostraba un fuerte interés por aprender.

Para evaluar el quehacer de este niño en particular y en los demás, se pensó en la construcción de un mapa conceptual ${ }^{10}$ que permitiría valorar el grado de dominio que tenían los pequeños sobre esta competencia para el trabajo intelectual, partiendo de su conocimiento teórico existente sobre el tema.

Su diseño pasó por distintas fases, que permitieron destacar su idoneidad: una primera versión del mapa conceptual ajustarse a los elementos teórico que describen conceptualmente que es un resumen escolar, Una segunda fase se centró en la valoración académica que hicieron dos expertos en el campo que dieran su opinión en relación a su elaboración: uno fue

\footnotetext{
${ }^{10} \mathrm{El}$ mapa conceptual es un recurso didáctico usado para dar una sinopsis de un tema en concreto a través de una representación gráfica del conocimiento que permite organizar y comprender ideas de manera significativa de un texto (Hidalgo, 2000:141).
} 
un lingüista especialista en el diseño de instrumentos de investigación, y un segundo, fue un maestro indígena en ejercicio de la región.

Tras incorporar los cambios destacados por estos expertos, en el campo se procedió a elaborar una nueva versión del mapa conceptual (Ver Figura 5).

Figura 5 - Mapa conceptual para evaluar el aprendizaje.

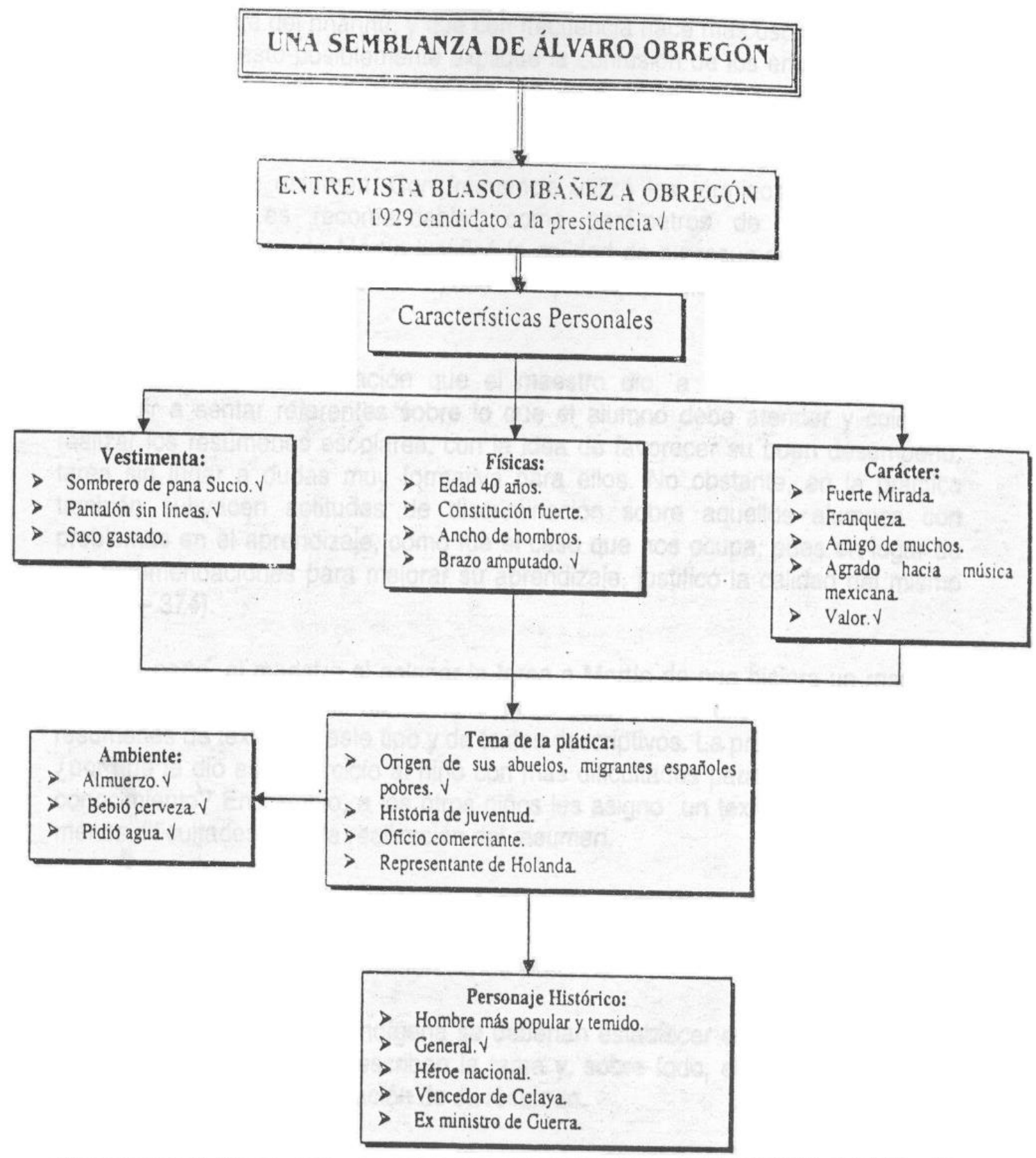

Fuente: Elaboración propia. 
El mapa conceptual final utilizado como instrumento para evaluar la producción de lo los niños está subdividido en cinco grandes bloques: 1) información general sobre el texto, donde se daba énfasis del título; 2) Aspectos relacionados con el sentido general del texto y apartados generales de la lectura; 3) Desarrollo de aspectos generales del personaje central de la lectura; 4) Aspectos referidos al tema de la plática; 5) Aspectos referidos a detalles de la vestimenta del personaje y 6).- que se reflejaban en las características históricas del héroe.

\section{Resultados del análisis}

A partir de un mapa conceptual, pudimos comprobar que éste niño que no había obtenido el dominio de esta competencia para el trabajo intelectual, según su profesor. Él tenía un dominio del contenido que había expresado por escrito con sus propias palabras. Si se analiza a detalle el resumen del niño "B" se puede apreciar que éste lo construyo con cada uno de los rubros que tiene el mapa conceptual, (Ver Figura 5) por tal motivo se puede concluir que el pequeño hizo bien la tarea asignada. Consecuentemente dejaba claro que el profesor estaba convencido que alumno "B" por ser un niño hñähnú no poseía las competencias académicas suficientes para hacer un resumen. Lo cual evidencia, que confrecuecia los infante que se consideran monolingües en lengua indígena, son los que más tienen limitaciones académicas. Sin embargo esta experiencia de enseñanza aprendizaje no necesariamente se cumplen con este estigma académico.

De manera más concreta se puede decir el niño "B" cuando se realizó la evaluación a partir del Figura 5 se comprobó que leyó y comprendió todo el texto, consecuentemente está preparado para la tarea de elaborar un resumen con sus propias palabras, a partir de texto fuente.

Consecuentemente, el niño hñahñu después de haber comprendido el texto a través de leer varias veces del mismo. Ahora la tarea podría ser más clara. Esto unido al hecho de que se le hubiera enseñado a construir un mapa conceptual con los datos más importantes del texto él estaría en condiciones de cumplir con la tarea asignada. Es decir estaría en condiciones de redactar dos posibles versiones del documento, una con la descripción de la ideas principales del autor y la otra la de dar una opinión sobre el texto, a partir del sentido del texto. Por lo tanto, el niño estaría en condiciones de adquirir esta competencia académica necesaria para el trabajo intelectual. 
Por lo tanto, elabora un resumen - destacando aquellas ideas propias del autor a partir de las cuales, se estaba de acuerdo o en desacuerdo de las mismas, significa enseñar a los niños a tener un juicio crítico sobre lo que leen, es decir tener una opinión sobre el otro y delimitar aquello en que se está de acuerdo o en desacuerdo. También implica identificar las ideas propias del otro, y al mismo tiempo se adquiere la posibilidad de fundamentar textos convenientes a una realidad académica como la que vivimos en nuestros días.

\title{
7 Hacia la representación de una diferente forma de enseñar los resúmenes
}

El sustituir una representación docente centrada en una forma mecánica en donde los resúmenes se enseñan como cualquier contenido mecánico, demanda la búsqueda de formas alternativas para su enseñanza.

\begin{abstract}
A menudo el lenguaje ha sido estudiado como si fuera un cadáver. De ahí que en la lingüística y en la enseñanza de las lenguas haya habido y siga habiendo tantas personas que indagan en la anatomía del lenguaje con una actitud semejante a la de los forenses y dedican sus esfuerzos filológicos y docentes a diseccionar el cuerpo inerte de la lengua a la búsqueda de sus células fonológicas, de sus viseras morfológicas, de sus sistema sintáctico y de su tejido léxico. Esta manera de entender del estudio del lenguaje es ineludible si lo que deseamos es conocer por dentro los entresijos gramaticales del lenguaje (Lomas,2007: 7).
\end{abstract}

A simple vista, realizar una tarea como la asignada a los niños hñähnú, de favorecer una competencia académica, no es un quehacer sencillo ya que implica tener un dominio del español como lengua oral y escrita, así como el manejo de un enfoque didáctico como el enfoque constructivista que propone Solé y Coll (2007)Es decir, aprender hacer un resumen escolar, implica entender que es un proceso, que lleva consigo haber leído con mucha calma la lectura asignada, y después eliminar los elementos considerados secundarios de un texto, preferentemente empleando un mapa de ideas, conservando siempre el núcleo de sentido y, al mismo tiempo, reformularlo mentalmente y parafraseándolo a través de un texto propio, de modo tal que el resultado sea un producto más pequeño coherente y cohesivo. En este contexto, el profesor que se dedique atender a los niños hñähnú en particular y niños indígenas en general, está obligado a tener los elementos lingüísticos y didácticos para atender a este tipo de estudiantes.

Hoy consideramos que para escribir un texto expositivo, al igual que cualquier otro tipo de texto, es necesario enseñarlo en las aulas y que conlleva esfuerzo y tiempo: lecturas variadas, reflexiones, planificación de ideas fundamentales y secundarias, revisiones múltiples, trabajo en equipo... (Cosio y otros2009:73). 
Otro problema en su enseñanza, se centra en seguir una secuencia de pasos: como leer detenidamente el texto, subrayar las ideas principales, colocar al lado de cada párrafo las palabras claves correspondientes y, por último, reescribir esas ideas principales en un texto articulado. Estos pasos suelen ser empleados de manera indiscriminada con cualquier tipo de texto: narrativo, descriptivo o expositivo, sin importar, si este es para una lección de historia, un cuento, una noticias periodísticas entre otros. Todos son enseñados de la misma manera como se pudo apreciar en la lección analizada.

Por ejemplo, en la clase observada, el profesor advierte la importancia de desarrollar esta competencia académica para el trabajo intelectual, de no enseñarla de manera aislada, solo centrada en los contenidos de los libros de español, es decir el busca mostrar cómo esta habilidad académica se puede emplear para el estudio de la historia, sin embargo, durante el tiempo de observación de la clase, él no los preparó para distinguir un texto narrativo, y la manera de cómo ser congruentes con elaboración.

Se puede decir que la enseñanza del resumen en educación primaria, es un proceso didáctico complejo como el ejemplo que aquí se expone, debe existir la comprobación de haber dominado las fases anteriores previas. Es decir la concepción del resumen como la que aquí se solicitó debe ser una habilidad debe ser construido en una etapa posterior al estudio. Por ejemplo comprobar que dentro de esta tarea sus alumnos, tienen un dominio de varias habilidades previas: tienen un dominio de la lectura de comprensión. 2.- saben subrayar previamente lo importante, y 3.- saben redactar lo seleccionado.

Sin embargo, como resultado de la actividad el docente está olvidando que la primera tarea es lograr que el estudiante comprenda el sentido del texto y después realizar la secuencia didáctica antes mencionada para la construcción de resúmes escolares.

Olvidar que lo primero es estudiar un texto es decir comprenderlo antes de analizarlo. El resumen es un discurso académico que busca explicar la estructura conceptual del mismo, lo cual implica saber cómo está organiza jerárquicamente la información de las secuencias del texto base, representando así la coherencia global del mismo. El concepto teórico que ha propuesto van Dijk (1983) para describir dicha coherencia es el de macro-estructura semántica. En pocas palabras realizar un resumen, sin tener la certeza que existe una comprensión del texto, implica olvidarse de la trascendencia de esta tarea, "el avance y el retroceso", la posibilidad de parar la lectura del texto, pensar su sentido, relacionar lo que se lee con lo que se vive en su contexto, efectuar sucesivas recapitulaciones, establecer 
relaciones entre las diferentes ideas, en un proceso progresivo de atribución de significaciones. Muy importantes para el desarrollo del trabajo intelectual.” (Solé, 1994).

Consecuentemente, consideramos que todo docente tiene que tener presente, el sentido de la tarea educativa, es decir, está obligado a trabar junto con sus alumnos una propuesta didáctica que los ayude a formarse como intelectuales, que sean capaces de construir las nuevas ideas de cambio y renovación que requieren los pueblos originarios. Hoy se requiere tener muchos hombres ñhäñhú que tengan el gusto por formarse también académicamente, para lo cual se requiere tener una complacencia personal por la lectura pero sobre todo tener la capacidad de fundamentar y defender sus propias ideas, de manera oral y también por escrito en su propia lengua, en español o la lengua que mejor considere pertinente.

Razonablemente saber enseñar un resumen, lleva implícito estar colaborando a que sea una realidad el derecho de la niñez a usar y estudiar su lengua materna, a que se fortalezca su identidad y, sobre todo, a que logre una educación acorde a la realidad que viven nuestros tiempos.

De manera sintética, se puede decir que la enseñanza de los resúmenes lleva implícito, formar buenos lectores y buenos productores de textos académicos, en el contexto de formar niños autónomos con relevantes hábitos de estudio. Es decir, se busca el fomento de crear una vida intelectual, que le permitirá a los estudiantes las habilidades para estudiar de por vida y aprender un forma de adquir el conocimiento, construido por el mismo, en contraposición al construido por otros autores, o con el soporte de otros respetando sus ideas. Es decir estamos en la antesala de comenzar a crear intelectuales productores de ideas que van a cambiar al mundo.

\section{Conclusiones}

Hoy los pueblos originarios no deben de perder la oportunidad marcada por muchos organismos internacionales y en México por los cambios legislativos existentes de fortalecer la cultura con los conocimientos que han legado nuestros antepasados, y tenemos la responsabilidad de protegerlos, cuidarlos, reproducirlos y enseñarlos a las nuevas generaciones, a los nuevos ciudadanos quienes en el futuro nos relevarán en nuestras responsabilidades (). Los docentes defensores de la causa de los pueblos originarios están obligados a superar la representación didáctica de hacer las cosas por hacerlas, y superar las formas tradiciones de enseñanza de competencias para el trabajo intelectual, es decir, es su 
deber conocer la necesidad de centrar la enseñanza en las habilidades propias de los niños e interpretar su realidad académica de acuerdo con el sentido que tiene desde un enfoque comunicativo funcional, ya que esto implica fortalecer su autonomía académica, como productores de texto académico, sustentados en soportes teóricos relevantes, que le son tan necesarios para combatir el estigma, que existe de que muchos de sus conocimientos no tienen la "validez" requerida en el contexto de la cultura occidental. Sabemos que la tarea no es fácil pero también estamos convencidos que existe en muchos docentes, la voluntad de hacerlo y que el enfoque que hoy se propone puede ayudar a cumplir más fácilmente con los ideales de los pueblos originarios. Es decir hoy requerimos formar alumnos productores de sus propios textos académicos, donde defiendan sus creencias y al mismo tiempo creemos que con voluntad, todo es posible. En este marco los convocamos a poner todo su empeño para la revitalización de la cultura hñahñu y mantener esta articulación entre el saber didáctico de cómo enseñar y los resultados académicos reales que necesitan los niños de ser productores de sus propios textos académicos.

\section{Referencias}

Candela, A. (1999). Ciencia en el Aula: los alumnos entre la argumentación y el consenso, México, Paidós.

Carrillo, A., Herrera C.A., Montero, G.(2017)"Docentes universitarios y de educación básica, haciendo juntos la tarea de recuperar una lengua en peligro de extinción, en México" en Fonseca, E. y Arauzo, C.S. Identidad y diversidad cultural en América Latina, Porto Alegre, Editora fi.

Cole, M.(1999). Psicología cultural: una disciplina del pasado y del futuro, Madrid: Morata.

Coll, C. y otros (2007) El constructivismo en el aula, Barcelona, Graó.

Cosio, M de J. y Pérez, E.(2009), La historia, una mirada diferente, en Nemirovsky, M.(Coord.), Experiencias escolares con la lectura y la escritura, Barcelona: Graó.

Cortés, R. (2011). Operaciones Textuales: Resumen. México: Portal Académico del CCH/UNAM.Recuperadodehttp://portalacademico.cch.unam.mx/alumno/tlriid2/unidad2/opera cionesTextuales/resumen (julio, 2013).

Chapela, L.M.(2005) Ventana a mi comunidad, el pueblo hñähnú, Cuadernillo Cultural, México: SEP/CGEIB.

Dirección General de Educación Indígena (DGEI)(2017) Hñähnú. Libro para el maestro. Educación primaria indígena y de la población migrante, México, DGEI. 
Essomba, M.A.,(coord.) (2007). "El proyecto de la educación intercultural”, en Essomba, M.A., Construir la escuela intercultural, reflexiones y propuestas para trabajar la diversidad étnica y cultural, Barcelona: Graó.

Erickson, F. (1997). "Métodos cualitativos de investigación sobre la enseñanza" En, Wittrock, (com.) La investigación de la enseñanza ll, Barcelona: Paidós.

Hidalgo, J.L.(2000) Constructivismo y aprendizaje escolar, Castellanos: México.

Lefebvre, H.(1983), La presencia y la ausencia, contribuciones a la teoría de las representaciones, México: Fondo de Cultura Económica.

Lionel, R. y Mozejko (2009) Gestión de las prácticas: opciones discursivas, Rosario Argentina, Homo Sampies.

Lomas, C. (1999), Cómo enseñar a hacer cosas con las palabras. Teoría y práctica de la educación lingüística. Vol. II, Barcelona, Paidós. Y enseñanza de la lengua.

Lomas, C., Osorno, A. y Tusón, A. (1997). Ciencias del lenguaje, competencia comunicativa y enseñanza de la lengua, Barcelona, Paidós.

Jolibert, J. y Jacob, J. (2015). Interrogar y producir textos auténtico: vivencias en el aula: equipo de profesores de Valparaiso y Puchuncavi, México: De Lirio.

(Jolibert, J. y Sraïki, C. (2006). Niños que construyen su poder de leer y escribir, Buenos Aires, Manantial.

INALI (2003) Ley General de los Derechos Lingüísticos de los Pueblos Indígenas. México: INALI.

INEE. (2017) Directrices para mejorar la atención educativa de niñas, niños y adolescentes indígenas. México: INEE.

INEE-UNICEF (2017) Panorama Educativo de la Población Indígena y Afrodescendiente, México: INEE-UNICEF.

Lomas, C.(2007) "Prólogo: Conciencia lingüística y educación” en Cots, J.M. y otros. La conciencia lingüística en la enseñanza de las lenguas, Barcelona, Graó.

Medina, J.L.(2006). La profesión docente y la construcción del conocimiento profesional, Buenos Aires: Magisterio del Río de la Plata.

Morollón, M.(2003) La diversidad cultural y sus conflictos, un camino hacia la interculturalidad, en Miguel Santos Guerra (coord.)Aprender a convivir en la escuela. Madrid, Universidad Internacional de Andalucía / Akal.

Nemirovsky, M. (2009) "La escuela: espacio alfabetizador" en Nemirovsky, M.(Coord.), Experiencias escolares con la lectura y la escritura, Barcelona: Graó. 
Sagastizabal, M.A., (2009). “Aprender y enseñar en las sociedades actuales” en Sagastizabal, M.A. (coord.). Aprender y enseñar en contextos complejos: multiculturalidad, diversidad y fragmentación, Buenos Aires: Noveduc.

Solé I. (1994) Estrategias de lectura. Barcelona: Graó/ICE.

Solé I. y Coll C. (2007) "Los profesores y la concepción constructivista" en Coll, C. y otros El constructivismo en el aula, Barcelona, Graó.

Stake, R.,(1999). La investigación con estudio de casos, Madrid: Morata.

Tardiff, M. (2004). Los saberes del docente y su desarrollo profesional. Madrid: Narcea.

Olmos, A. y Carrillo, A. (2009). Juego y Alfabetización: bases para un sistema educativo cultural vygotskiano. México, UNAM- Miguel Ángel Porrúa.

Vygotski, L.S. (1978). El desarrollo de los procesos psicológicos superiores, Barcelona, Crítica.

Vygotski, L.S. (1982). Psicología del arte, Barcelona, Barral.

Submetido em 05 de julho de 2019.

Aceito em 08 de agosto de 2019.

Publicado em 09 de agosto de 2019. 